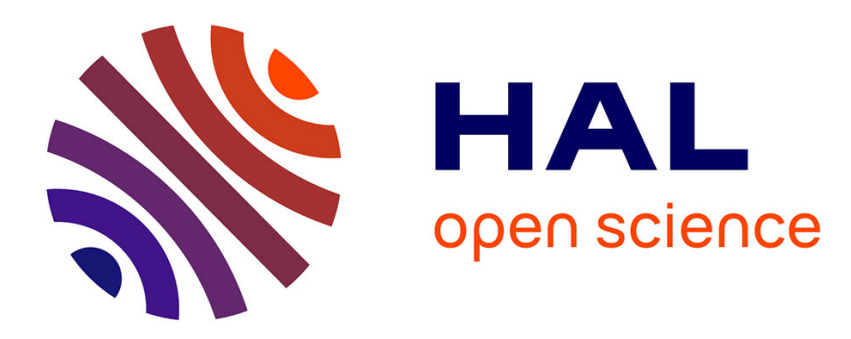

\title{
Microstructure and mechanical properties of pressureless sintered alumina-silver composites
}

J. Wang, C. Ponton, P. Marquis

\section{To cite this version:}

J. Wang, C. Ponton, P. Marquis. Microstructure and mechanical properties of pressureless sintered alumina-silver composites. Journal de Physique IV Proceedings, 1993, 03 (C7), pp.C7-1769-C7-1774. 10.1051/jp4:19937280 . jpa-00251922

\section{HAL Id: jpa-00251922 https://hal.science/jpa-00251922}

Submitted on 1 Jan 1993

HAL is a multi-disciplinary open access archive for the deposit and dissemination of scientific research documents, whether they are published or not. The documents may come from teaching and research institutions in France or abroad, or from public or private research centers.
L'archive ouverte pluridisciplinaire HAL, est destinée au dépôt et à la diffusion de documents scientifiques de niveau recherche, publiés ou non, émanant des établissements d'enseignement et de recherche français ou étrangers, des laboratoires publics ou privés. 


\title{
Microstructure and mechanical properties of pressureless sintered alumina-silver composites
}

\author{
J. WANG, C.B. PONTON and P.M. MARQUIS
}

IRC in Materials for High Performance Applications and School of Metallurgy and Materials, The University of Birmingham, Birmingham B15 2TT, U.K.

\begin{abstract}
The silver toughened alumina ceramics, which were fabricated via a conventional ceramic processing route using commercially available alumina and silver oxide powders as the starting materials, exhibit a higher fracture toughness (6 to $9 \mathrm{MPam}^{0.5}$ ) than the monolithic alumina ceramic ( 2.5 to $3.0 \mathrm{MPam}^{0.5}$ ). The weak interfacial bonding between the silver inclusions and the alumina matrix is characterised by the occurrence of voids or pores at the interface, the formation of which is due to the high vapour pressure of molten silver at the sintering temperature. The thermal expansion mismatch between the metallic phase and the ceramic matrix generates residual strains in the composite structure. A microstructural study using in-situ TEM observation showed that the thermal strains were accommodated largely by the silver grains, which are much more deformable than the rigid alumina grains. Both the well established dislocation rings and deformation twins were observed to occur in the silver grains entrapped at the grain boundaries and grain junctions of the alumina matrix.
\end{abstract}

\section{Introduction}

A number of metallic phase toughened ceramic materials have been fabricated and microstructurally characterised, including lanxide aluminium toughened alumina [1], nickel toughened alumina and mullite [2], and more recently silver toughened alumina [3]. A fracture toughness of 7 to $8 \mathrm{MPam}^{0.5}$ is obtainable for these metallic phase dispersed ceramic matrices via a careful compositional and microstructural control, compared to a fracture toughness of 2.5 to $3.0 \mathrm{MPam}^{0.5}$ for the monolithic ceramic matrices. The presence of a metallic inclusion in the ceramic matrix results in crack bridging by the stretched metallic phase and crack deflection at the interface between the metallic phase and the ceramic when the composite material is fractured [4].

The fabrication of silver toughened ceramic matrices, which has been carried out using conventional ceramic processing route, e.g., pressureless sintering of mixed alumina and silver oxide powder compacts, is both simple and economical [3]. During the sintering of an alumina-silver oxide powder compact, a series of physical and chemical changes take place with increasing heating temperature. For example, the silver oxide particles undergo decomposition in the temperature range of 400 to $450^{\circ} \mathrm{C}$, forming metallic silver inclusions within the alumina matrix. The metallic silver particles then melt at $962^{\circ} \mathrm{C} \mathrm{[5].} \mathrm{The} \mathrm{high} \mathrm{vapour} \mathrm{pressure} \mathrm{of} \mathrm{molten} \mathrm{silver} \mathrm{results} \mathrm{in} \mathrm{a} \mathrm{significant}$ decrease in silver content at the sintering temperature and a silver-free alumina sintered surface, the thickness of which varies with composition and sintering temperature, has been found in the pressureless sintered alumina-silver composites [3]. The aim of the present work is to carry out a study on the microstructure and mechanical properties of the pressureless sintered alumina-silver composites. 


\section{Experimental Work}

The fabrication procedure for the pressureless sintered silver toughened alumina has been detailed elsewhere [3]. The as-sintered alumina-silver composite exhibited a sintered density in the range of 96.5 to $99.2 \%$ theoretical density. As a result of the high vapour pressure of molten silver at the sintering temperature, the average silver content in each as-sintered sample is lower than that in the pre-sintered powder compact. Furthermore, a silver-free alumina sintered surface forms, the thickness of which varies from 10 to $180 \mu \mathrm{m}$ with composition and sintering temperature and time. The average silver content in each specimen was worked out on the basis of the measured weight loss and the observed thickness of the silver-free alumina surface layer. The mechanical property characterisation for these pressureless sintered alumina-silver composites include Vickers' indentation testing for fracture toughness and hardness at a load of $196 \mathrm{~N}[6]$ and three point flexural strength up to $1000^{\circ} \mathrm{C}$. SEM was used to characterise both the polished and fracture surfaces. To prepare specimens for the insitu TEM study, a slice of $300 \mu \mathrm{m}$ in thickness was cut from the as-sintered ceramic containing 10.1 vol\% Ag using a diamond slicing wheel, followed by grinding on 400 grit $\mathrm{SiC}$ paper to reduce the thickness of the slice to approximately $150 \mu \mathrm{m}$. Discs of $3 \mathrm{~mm}$ in diameter were obtained from the slice using a diamond disc cutter. The specimen discs were further polished and then dimpled, and followed by ion beam thinning. The in-situ TEM microstructural study was carried out on the ion beam thinned foils using a Joel-4000CX at $400 \mathrm{kV}$.

\section{Results and Discussion}

The microstructure of the pressureless sintered $\mathrm{Al}_{2} \mathrm{O}_{3}-\mathrm{Ag}$ composites is largely dependent on the composition and sintering temperature and time. The grain sizes of the intergranularly positioned silver inclusions, which exhibit an elongated morphology along the grain boundaries of the alumina matrix, were observed to be in the range of 1 to $5 \mu \mathrm{m}$. Silver particle agglomerates of intermediate sizes $(5$ to $10 \mu \mathrm{m})$ were occasionally seen. The average grain size of the alumina matrix was measured to be in the range of 5 to $8 \mu \mathrm{m}$ for the compositions containing 6.6 to $12.4 \mathrm{vol} \% \mathrm{Ag}$, decreasing with increasing silver content.

Figure 1 shows the three point bend strength as a function of test temperature for the alumina matrix containing $10.1 \mathrm{vol} \% \mathrm{Ag}$. The fracture strength decreases steadily with increasing test temperature up to $1000^{\circ} \mathrm{C}$, which is above the melting point of metallic silver. Obviously, the decrease in fracture strength with increasing test temperature is, to a large extent, due to the progessive softening of the silver inclusions with rising temperature. Figure 2 shows the Vickers' indentation toughness as a function of silver content for the compositions sintered at $1600^{\circ} \mathrm{C}$ for 2 hours. The fracture toughness increases with increasing silver loading over the composition range of 0 to $10 \mathrm{vol} \%$ $\mathrm{Ag}$, up to a maximum and then decreases slightly for silver content above $10 \mathrm{vol} \%$. The decrease in indentation toughness for the high silver-loading compositions is considered to be due to the formation of large microstructural flaws such as cracks, induced by the thermal expansion mismatch between the metallic phase $\left(20 \times 10^{-6} /{ }^{\circ} \mathrm{C}\right)$ and the oxide phase $\left(7 \times 10^{-6} /{ }^{\circ} \mathrm{C}\right)$. As with other two phase materials, the total strain energy level associated with the thermal mismatch in the $\mathrm{Al}_{2} \mathrm{O}_{3}$ - $\mathrm{Ag}$ composites increases with an increase in silver content. A network of residual cracks will be generated when the residual strain energy level is above a critical value $[7,8]$. The occurrence of residual cracks in these high silver-loading composites was confirmed indirectly by the dependence of the Vickers hardness on silver content. The decrease in Vickers hardness with increasing silver content at $>10$ vol\% Ag was larger than that theoretically expected on the basis of the rule of mixture.

Figures $3(A, B)$ are two bright field TEM micrographs of the representative microstructure for the alumina-silver composite containing $10.1 \mathrm{vol} \% \mathrm{Ag}$. It consists of an alumina matrix of 3 to $10 \mu \mathrm{m}$ in grain sizes and silver inclusions ranging in size from 1 to $5 \mu \mathrm{m}$, situated both at the grain boundaries and grain junctions of the alumina matrix. Somewhat smaller silver particles, in the range of 0.1 to 2 $\mu \mathrm{m}$ in sizes, were observed to occur within certain alumina grains (also see Figure 5). The silver inclusions were found to exhibit widely differing morphologies with respect to their sizes and locations within the alumina matrix: (i) the relatively larger silver grains at the grain junctions of the alumina matrix exhibit an elongated morphology along the grain boundaries; (ii) the intermediately sized silver phase at the grain boundaries of the alumina matrix exhibit a near-ellipsoidal morphology; and (iii) the relatively smaller silver particles entrapped within alumina grains are near-spherical in morphology. Voids or pores often exist at the interface between the silver grains and the alumina matrix. 

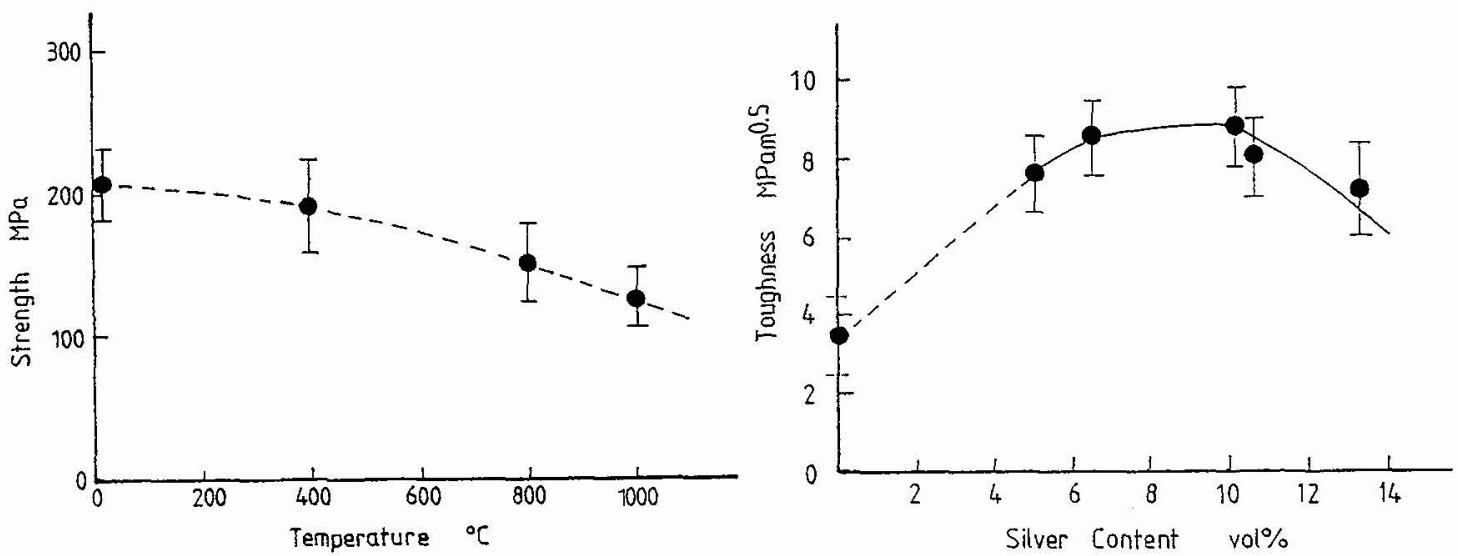

Figure 1: Three point flexural strength as a function Figure 2: The Vickers' indentation toughness as a of test temperature for the alumina matrix containing function of silver content for the $\mathrm{Al}_{2} \mathrm{O}_{3}-\mathrm{Ag}$ composites $10.1 \mathrm{vol} \% \mathrm{Ag}$, sintered at $1600^{\circ} \mathrm{C}$ for 2 hours. sintered at $1600^{\circ} \mathrm{C}$ for 2 hours.

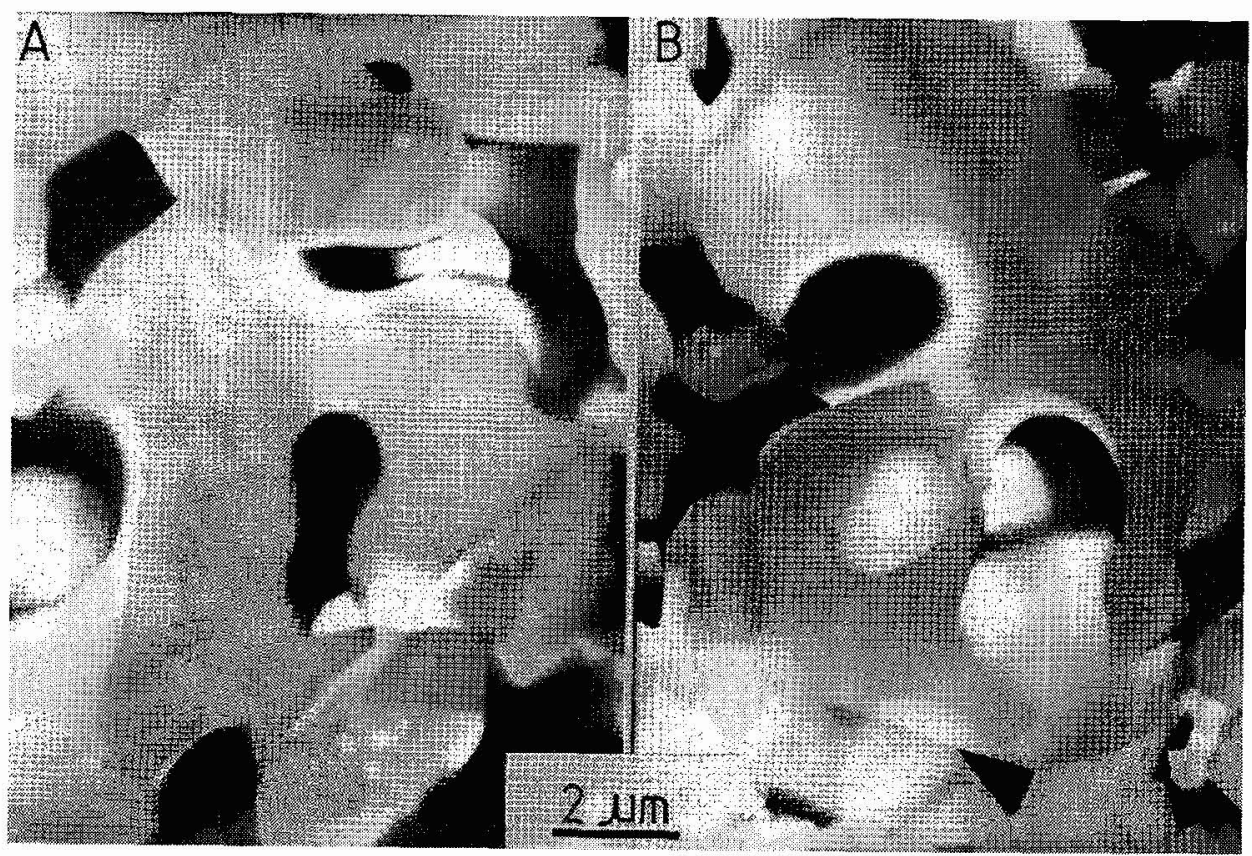

Figures 3(A,B): Two bright field TEM micrographs showing the microstructure of the alumina matrix containing $10.1 \mathrm{vol} \% \mathrm{Ag}$. 
The formation of voids or pores at the interface between the silver grains and the alumina matrix is closely related to the high vapour pressure of molten silver at the sintering temperature [9]. Owing to the high vapour pressure, on one hand, Ostwald ripening may be the dominant mechanism responsible for the growth of silver grains dispersed in the alumina matrix [10]. On the other hand, a back stress will be associated with the high vapour pressure of the molten silver phase, which will offset a degree of driving force for the densification of the alumina matrix. The disappearance of a silver inclusion or part of a silver inclusion will leave a void in the alumina matrix, although further densification may eventually eliminate the void from the structure. The release of vaporized silver from the alumina matrix requires a well interconnected channel network. It is likely that the grain boundaries will act as such diffusion channels for the vaporized silver phase entrapped at the grain boundaries and grain junctions of the alumina matrix. It is, however, almost impossible for the vaporized silver entrapped within an alumina grain to be released, as no interconnected channels available. The entrapped silver vapour may generate an internal pressure at the interface between the alumina and the molten silver phase, limiting the densification attained in this region. This explains the observation that the interfacial voids or pores are more likely to occur around the silver grains or the sections of silver grains entrapped by the alumina grains. The existence of these interfacial voids will facilitate the occurrence of crack deflection, which was observed to be an important toughening mechanism in the silver toughened alumina ceramics.

The thermal mismatch between the metallic phase and the oxide phase is an important factor in the generation of microstructure for the silver dispersed alumina matrix. The linear thermal expansion coefficient of metallic silver $\left(20 \times 10^{-6} \mathrm{C}^{-1}\right)$ is almost three times of that for alumina ceramics $\left(7 \times 10^{-6}\right.$ $\left.\mathrm{C}^{-1}\right)$. On cooling at temperatures below the melting point of metallic silver $\left(962^{\circ} \mathrm{C}\right)$, a thermal stress will be generated in the composite structure. Due to thermal mismatch, microcracks occur at the interface in many ceramic matrix composite systems [11]. The distribution of the thermal mismatchinduced residual strain energy is dependent on the elastic properties of the component phases. The alumina grains exhibit a higher elastic modulus ( $380 \mathrm{GPa})$ than the metallic silver (105 GPa). Under a given stressing condition, the former will undergo a lower degree of deformation than the latter. As shown in Figures 4(A,B), few strain contours and dislocation networks were observed to occur in the alumina grains, indicating that these rigid alumina grains accommodate a very small proportion of the total residual strain caused as a result of the thermal mismatch.

By contrast, silver grains entrapped at the grain boundaries and grain junctions of the alumina matrix exhibit either a well defined dislocation network or deformation twins or both. Microcracks were not found at the interface between the silver inclusions and the alumina matrix, regardless of the differences in particle size and morphology of various silver grains observed. Selected area electron diffraction confirmed that the deformation twinning occurs on the $\{111\}$ planes. No correlation was found between the orientation of alumina grains and the twinning orientation of the silver inclusions, as the thermal stress field at a grain boundary or grain junction of the alumina matrix is highly anisotropic and complex in nature. In-situ TEM observation showed that the deformation twins occurred in both the parallel and perpendicular directions to the c-axis of the alumina grains.

As discussed earlier, certain small silver inclusions, which exhibit a rounded grain morphology, are entrapped within alumina grains. The strain field associated with these intragranularly positioned silver grains may be different from that associated with the intergranularly positioned silver grains, due to their difference in size and in grain morphology [7]. Well developed strain contours were observed to occur in almost all these rounded silver particles, regardless of their size and shape, see Figures 5(A,B). Dislocation rings were found to occur only in the relatively larger silver particles entrapped within the alumina grains. Deformation twins, however, were not found in these intragranularly positioned silver grains when more 60 grains were studied, although some of these silver grains were highly strained.

The level of thermal mismatch-induced residual strain energy in a two phase material is dependent on parameters such as the differences in the thermal and elastic properties of the two component phases, and in size and shape of the second phase in the matrix [8]. The residual strain energy increases with increasing particle size of the second phase. An angular inclusion is likely to result in a higher strain concentration at the interface than does a rounded one. As discussed above, the intragranularly positioned silver grains are relatively smaller in size and more rounded in morphology than those entrapped at the grain boundaries and grain junctions of the alumina matrix. The thermal mismatch-induced residual strain energy associated with these intragranularly positioned silver particles is therefore expected to be lower than that associated with the intergranularly positioned silver grains. A critical or threshold minimum strain energy is required in order to generate either a dislocation ring or a deformation twin in the face-centred cubic silver. Specifically, the strain energy needed to induce a deformation twin is generally higher than that needed to induce a dislocation ring 

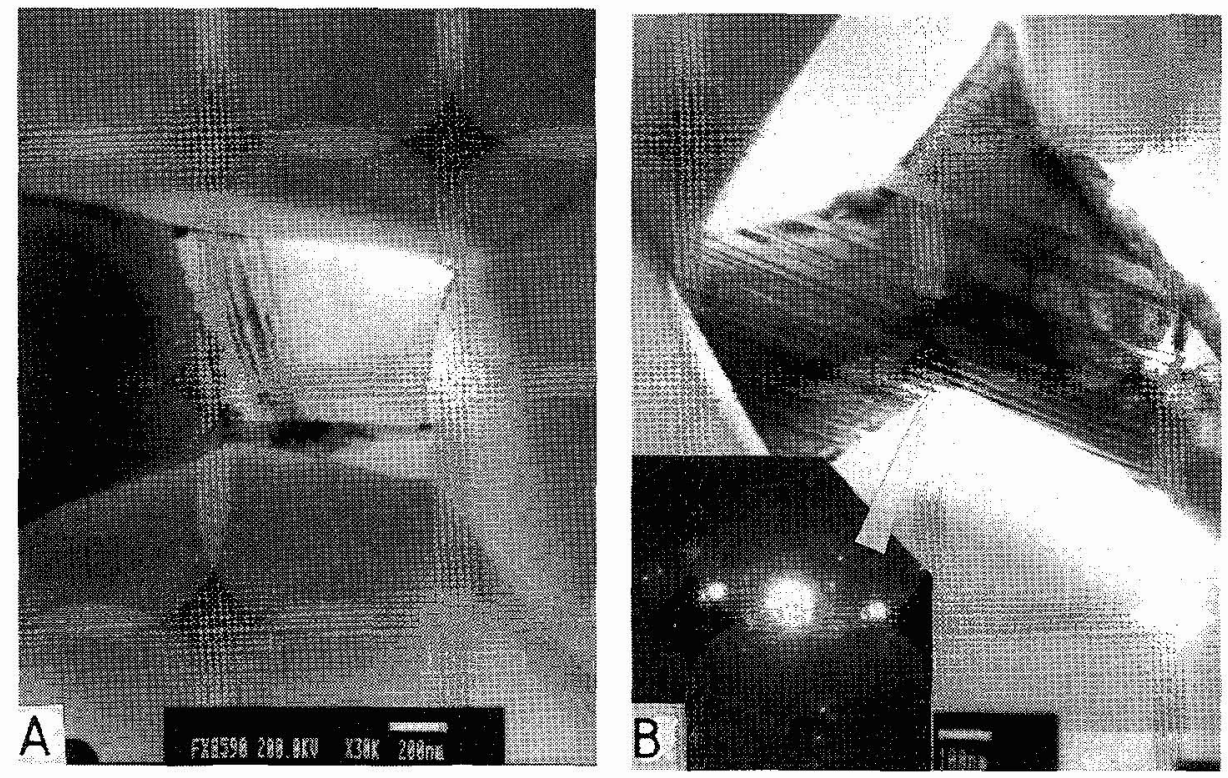

Figures $4(A, B)$ : Bright field TEM micrographs and the associated SAD patterns showing the deformation twins in the silver grains entrapped at the grain boundaries and grain junctions of the alumina matrix.
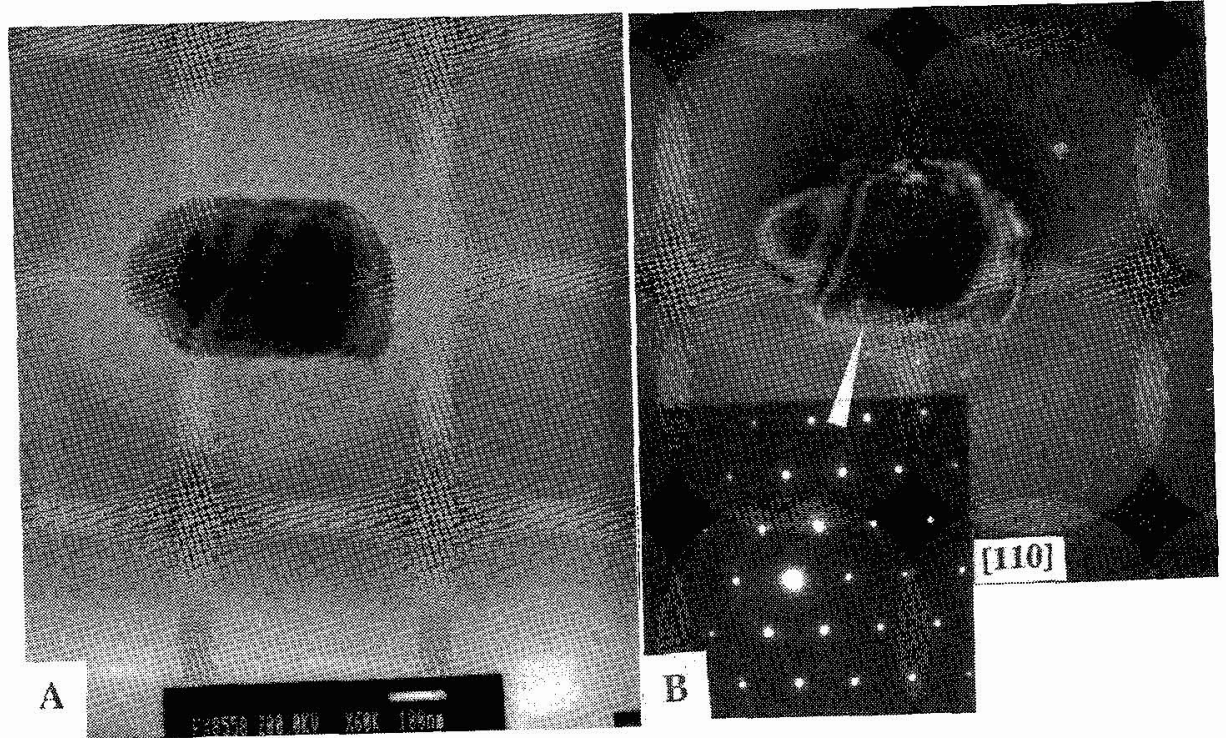

Figures 5(A,B): Bright field, dark field TEM images and associated SAD pattern showing a highly strained silver inclusion entrapped within an alumina grain. 
in metallic silver, if it is assumed that the formation of the deformation twin is via a dislocation mechanism. The thermal mismatch-induced residual strain energy in the intragranularly positioned silver particles may not be high enough to result in the formation of deformation twinning on cooling from the sintering temperature. This explains the absence of deformation twins in these small and rounded silver grains.

\section{Conclusions}

A study has been made of the microstructure and mechanical properties of pressureless-sintered alumina-silver composites, which consists of both intergranularly and intragranularly positioned silver inclusions in the alumina matrix. The materials exhibit an increasing indentation toughness with increasing silver loading over the composition range of 0 to $10 \mathrm{vol} \% \mathrm{Ag}$. A further increase in silver loading above $10 \mathrm{vol} \%$ results in a decrease in fracture toughness, due to the occurrence of microstructural defects such as cracks. The weak interfacial bonding between the silver inclusions and the alumina matrix is characterised by the occurrence of voids or pores at the interface. Well established dislocation rings or deformation twins or both occur in the intergranularly positioned silver particles, caused by the large thermal mismatch between the metallic phase and the ceramic matrix.

Acknowledgements: The authors wish to thank M. Pracher for his involvement in part of the experimental work described in the present work and the SERC for financial support.

\section{References}

1. Newkirk M.S, Lesher H.D, White D.R., Kennedy C.R, Urquhart A.W.and Claar T.D., Ceram. Eng. Sci. Proc., 8, (1987) 879.

2. Bannister M, Shercliff H., Bao G, Zok F and Ashby M.F, Acta Metall., 40, (1992) 1531.

3. Wang J., Ponton C.B and Marquis P.M.,"Silver Toughened Alumina". Bri. Ceram. J. Trans. (1993) in press.

4. Ashby M.F., Bunt F.J. and Bannister M., Acta Metall., 37, (1989) 1847.

5. Lide D.R., CRC Handbook of Chemistry and Physics. CRC Press, Boston, (1992) p.4-123.

6. Anstis G.R., Chantikul P., Lawn B.R and Marshall D.B., J. Amer. Ceram. Soc., 64, (1981) 533.

7. Lange F.F., "Fracture Mechanics of Ceramics", Vol.1. Edited by R.C. Bradt, D.P.H. Hasselman and F.F. Lange, Plenum Press, NY (1978).

8. Davidge R.W and Green D.J., J. Mater. Sci., 3, (1968) 69.

9. Alcock C.B, CRC Handbook of Chemistry and Physics. CRC Press, Boston, (1992) p.5-70.

10. Wengrenovitch R.D, Acta Metall., 30, (1982) 1079.

11. Becher P.F., J. Amer. Ceram. Soc., 74, (1991) 255. 